〈論

文〉

\title{
分散分析による水質測定計画の測定頻度の 最適化に関する研究
}

Study on optimization method of sampling frequency by analysis of variance for water quality surveillans

$\begin{array}{ccccc}\text { 岡 敬 一* } & \text { 吉 見 洋* } & \text { 井 口 潔* } & \text { 小森谷 廣子** } \\ \text { Keiichi OKA } & \text { Hiroshi YOSHIMI } & \text { Kiyoshi IGUCHI } & \text { Hiroko KOMORIYA }\end{array}$

\begin{abstract}
This study was aimed to present the procedure to obtain the optimized intervals of the seasonal and diurnal sampling in "Measurement Program" that the Governmental and prefectural agencies have been performing for more than ten years. In order to obtain the optimum sampling frequencies, the equation for maximizing the amount of information on the seasonal and diurnal variation was derived from an analysis of variance.

This method was successfully applied to the analysis of the rivers in the Kanagawa prefecture and the results showed that the attentions to the areal characteristics should be paid to intend the reasonable sampling strategies.

Key words: sampling frequency, analysis of variance, sampling program
\end{abstract}

\section{1。はじめに}

1970年に水質污濁防止法が制定されて以来，国及び 各地方公共団体は，水質測定計画に基づき，公共用水 域の水質污濁の状況を恒常的に監視してきている。水 質測定計画の当初目的は, 工場, 事業場排水の公共用 水域への影響の監視及び発生源規制施策の効果把握に 重点が置かれていた。しかし, 現在ではその内容も, 個 別発生源や限定支川を対象としたものではなく，流域 面全体を対象とした，広域的から総合的な水質改善施 策の企画，立案に活用できる基礎データの収集へと， 重点が移行しつつあるものと考光られる。

こうした水質污濁問題の変遷とともに, 水質測定計 画に抢ける調査地点数, 測定項目数は増加し続けてい る。例穴ば, 神奈川県では, 1972年から1983年の間に, 河川に抢ける調査地点数は62から79へ, また, 測定項 目数は22から 32 亿, それぞれ増加した。しかも, 採 水の頻度が全地点同一のため, データ量は増加の一途 をたどっている。

このよらなデータ量の増加にもかかわらず，現行の 水質調査では，流域特性から生ずる水質変動の地点間
差異を考慮したものとはなっていない。すなわち，各 地点の水質を統計的に比較してみる時，データ量は同 じだが，平均值の信頼区間が異なる等，得られた統計 量には質的な差があり，一律に評価することは適当で はないと言える。

従来の採水頻度に関する検討では, 年平均值と標準 偏差から求めた変動係数を一定の大きさに収めるよう に年間の採水頻度を求める方法等 ${ }^{114)}$ が採られて来て いる。しかし，こうして得られた年間の採水頻度を， 1 日当り何回採水し，それを年に何日行らか割り振る とき, 季節変動や時間変動を適確に捕えるための, 最 適頻度に関する理論的検討はなされていない。

そこで, 本研究では, 分散分析から出発することに より, 測定地点及び測定項目ごとに季節変動と時間変 動の大きさを比較し，これらの変動を適確に捕えるた めの採水頻度を求める式を導出し, 地点間で平均値の 信頼区間を同一にする方法を検討した。

\section{2. 使用データ}

生活環境項目を中心として, 1979 81年度の 3 ヶ年

* 神奈川県公害センター テ241 横浜市旭区二俣川 1-87-1, Kanagawa Prefectural Environmental Center, 1-87-1, Futamatagawa, Asahi-ku, Yokohama, 241 Japan

** 神奈川県工業試験所 $\bar{\top} 236$ 横浜市金沢区昭和町3173, Industrial Research Institute of Kanagawa Prefecture, 3173, Shouwa -machi, Kanazawa-ku, Yokohama, 236 Japan 
分の測定結果5 -7)から, 河川71地点, 11項目を選び解析 に用いた。項目扣よび現行の採水頻度をTable 1 亿示 した。また，筆者らが提案している河川の総合水質指 標 $(\mathrm{WQI})^{8), 9}$ も利用して解析を行った。

\section{3. 解析方法}

水質変動は，人間活動や自然要因に上る各種の周期 的な変動が，その大部分を占めているものと考光られ る。その中でも，採水間隔の影響を受ける周期的な変 動として, 時間変動と季節変動が考兄られる。そこで, 分散分析を行い，時間変動々季節変動を分離すること を試みた。

年変動は，長期的には傾向変動を表していると考兄 られるが, 短期的には季節変動の繰り返しと考光られ, また，神奈川県における BOD 等生活環境項目の河川 水質は, 最近数年間は横ばいの状況にあるので, 3 年 を繰り返しとする分散分析を, 地点別, 項目別に行っ た。

分散分析から最適頻度を求める解析手順を, Fig. 1 に示した。

\section{4.式の導出}

\section{1 最適頻度式の導出}

本研究で用いた，時間抢よび季節を要因とする分散 分析の二元配置モデル式は,

$$
\mathrm{x}_{i j}=\mu+\alpha_{i}+\beta_{j}+\varepsilon_{i j}
$$

$$
\begin{aligned}
\text { ここに, } & \\
\mathrm{x}_{i j} & : i \text { 月の測定日の } j \text { 回目のデータ } \\
\mu & : \text { 母平均値 } \\
\alpha_{i} & : i \text { 月の効果 } \\
\beta_{j} & : j \text { 回目の効果 } \\
\varepsilon_{i j} & : \mathrm{x}_{i j} \text { に含まれる残査 }
\end{aligned}
$$

と表される。(1)式のモデルによる分散分析表はTable 2 亿示す通りである。以下, Table 2 から最適頻度式を 導出する。

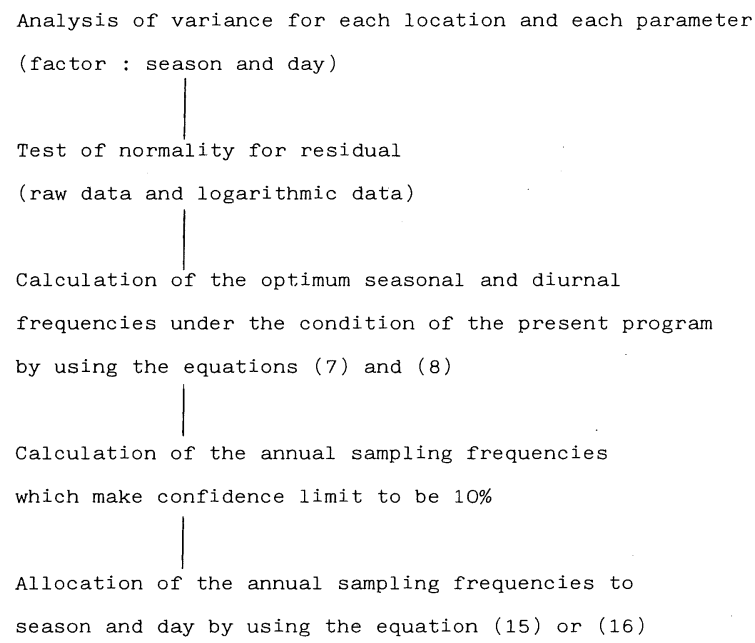

Fig. 1 Analytical procedure.

Table 1 Parameters used in the analysis and the present sampling frequencies

\begin{tabular}{ll}
\hline \multicolumn{1}{c}{ Parameter } & \multicolumn{1}{c}{ Sampling frequency } \\
\hline $\mathrm{pH}, \mathrm{DO}, \mathrm{BOD}, \mathrm{COD}, \mathrm{SS}$ & 4 times at 6 -hour intervals $/$ day $\times$ \\
& 1 day $/$ month $\times 12$ months $/$ year $=48$ times $/$ year \\
\hline $\mathrm{PO}_{4}-\mathrm{P}, \mathrm{T}-\mathrm{N}, \mathrm{NH}_{4}-\mathrm{N}, \mathrm{NO}_{2}-\mathrm{N}$, & 2 times at 12 -hour intervals $/$ day $\times$ \\
$\mathrm{NO}_{3}-\mathrm{N}, \mathrm{Cl}^{-}, \quad(\mathrm{WQI})$ & $1 \mathrm{day} /$ month $\times 12$ months $/$ year $=24$ times $/$ year \\
\hline
\end{tabular}

Table 2 Analysis of variance table corresponding to the model in this study

\begin{tabular}{cclll}
\hline Factor & $\mathrm{S}$ & \multicolumn{1}{c}{$\mathrm{F}$} & \multicolumn{1}{c}{$\mathrm{V}$} & $\mathrm{E}(\mathrm{V})$ \\
\hline $\mathrm{A}$ & $\mathrm{S}_{\mathrm{A}}$ & $\mathrm{F}_{\mathrm{A}}=\mathrm{k}-1$ & $\mathrm{~V}_{\mathrm{A}}=\mathrm{S}_{\mathrm{A}} / \mathrm{F}_{\mathrm{A}}$ & $\sigma_{\sigma_{\mathrm{E}}{ }^{2}+l \times \sigma_{\mathrm{A}}{ }^{2}}$ \\
$\mathrm{~B}$ & $\mathrm{~S}_{\mathrm{B}}$ & $\mathrm{F}_{\mathrm{B}}=l-1$ & $\mathrm{~V}_{\mathrm{B}}=\mathrm{S}_{\mathrm{B}} / \mathrm{F}_{\mathrm{B}}$ & $\sigma_{\mathrm{E}}{ }^{2}+\mathrm{k} \times \sigma_{\mathrm{B}}{ }^{2}$ \\
$\mathrm{E}$ & $\mathrm{S}_{\mathrm{E}}$ & $\mathrm{F}_{\mathrm{E}}=(\mathrm{k}-1) \times(l-1)$ & $\mathrm{V}_{\mathrm{E}}=\mathrm{S}_{\mathrm{E}} / \mathrm{F}_{\mathrm{E}}$ & $\sigma_{\mathrm{E}}{ }^{2}$ \\
\hline $\mathrm{T}$ & $\mathrm{S}_{\mathrm{T}}$ & $\mathrm{F}_{\mathrm{T}}=\mathrm{k} \times 1-1$ & $\mathrm{~B}:$ diurnal \\
\hline $\mathrm{A}:$ seasonal & $\mathrm{T}:$ total \\
$\mathrm{E}:$ residual & $\mathrm{F}:$ degree of freedom \\
$\mathrm{S}$ : sum of square & $\mathrm{E}(\mathrm{V}):$ expectation of mean square \\
$\mathrm{V}$ :mean square & $l:$ diurnal sampling frequency \\
$\mathrm{k}:$ seasonal sampling frequency & &
\end{tabular}


総変動 $\mathrm{S}_{\mathrm{T}}$ は次式で表される。

$$
\mathrm{S}_{\mathrm{T}}=\mathrm{S}_{\mathrm{A}}+\mathrm{S}_{\mathrm{B}}+\mathrm{S}_{\mathrm{E}}
$$

不偏分散 $\mathrm{V}$ の期待值は $\mathrm{E}(\mathrm{V})$ だから, 季節変動の不 偏分散 $V_{\mathrm{A}}$ に期待值 ${\sigma_{\mathrm{E}}}^{2}+1 \times \sigma_{\mathrm{A}}{ }^{2}$ 代入し, さらに季節 変動の自由度 $\mathrm{F}_{\mathrm{A}}$ に $\mathrm{k}-1$ を代入すると, 季節変動の平 方和 $\mathrm{S}_{\mathrm{A}}$ は(3)式で表される。

$$
\mathrm{S}_{\mathrm{A}}=(\mathrm{k}-1) \times\left({\sigma_{\mathrm{E}}}^{2}+\mathrm{l} \times{\sigma_{\mathrm{A}}}^{2}\right)
$$

同様に時間変動の平方和 $\mathrm{S}_{\mathrm{B}}$ と残査の平方和 $\mathrm{S}_{\mathrm{E}}$ を求め ると(4)，(5)式となる。

$$
\begin{aligned}
& \mathrm{S}_{\mathrm{B}}=(1-1) \times\left({\sigma_{\mathrm{E}}}^{2}+\mathrm{k} \times{\sigma_{\mathrm{B}}}^{2}\right) \\
& \mathrm{S}_{\mathrm{E}}=(\mathrm{k}-1) \times(1-1) \times{\sigma_{\mathrm{E}}}^{2}
\end{aligned}
$$

(3)，(4)，(5)式を(2)式に代入すると, 総変動 $\mathrm{S}_{\mathrm{T}}$ は(6)式で 表される。

$$
\mathrm{S}_{\mathrm{T}}=1 \times(\mathrm{k}-1) \times{\sigma_{\mathrm{A}}}^{2}+\mathrm{k} \times(\mathrm{l}-1) \times{\sigma_{\mathrm{B}}}^{2}+(\mathrm{k} \times
$$

$1-1) \times{\sigma_{\mathrm{E}}^{2}}^{2}$

ここで, 各要因の母分散 ${\sigma_{\mathrm{A}}}^{2},{\sigma_{\mathrm{B}}}^{2},{\sigma_{\mathrm{E}}}^{2}$ は, 母集団では 採水頻度 $\mathrm{k}$ とlによらない変数なので, 総変動 $\mathrm{S}_{\mathrm{T}}$ は $\mathrm{k}$ とlの関数と考光ることができる。そこで， 1 年間の採 水頻度を $\mathrm{n}(\mathrm{n}=\mathrm{k} \times \mathrm{l})$ とし, $\mathrm{S}_{\mathrm{T}}$ を連続関数と考光, $\mathrm{dS}_{\mathrm{T}} /$ $\mathrm{dk}=0$ と置き, $\mathrm{S}_{\mathrm{T}}$ を最大にする $\mathrm{k}$ と 1 を求めると $(7)$, (8)式となる。

$$
\begin{aligned}
& \mathrm{k}=\sqrt{\mathrm{n} \times{\sigma_{\mathrm{A}}}^{2} /{\sigma_{\mathrm{B}}}^{2}} \\
& \mathrm{l}=\sqrt{\mathrm{n} \times{\sigma_{\mathrm{B}}}^{2} /{\sigma_{\mathrm{A}}}^{2}}
\end{aligned}
$$

(7)，(8)式の $\mathrm{k}$ とl值のとき， $\mathrm{S}_{\mathrm{T}}$ は最大となるが，実 際には $\mathrm{k}$ と は整数值をとり, $\mathrm{k} \times 1=\mathrm{n}$ を満たすため, 適当な值に近似することになる。

\section{2 信頼限界を一定にする採水頻度式の導出}

(7), (8)式から求められる， $\mathrm{S}_{\mathrm{T}}$ を最大にする $\mathrm{k}$ とにを (6)式に代入し, 現行の水質調査から予測される最大の 総変動 $\mathrm{S}_{\max }$ を求める。次に, 平均値の $95 \%$ 信頼区間は, $\mathrm{t}$ 分布で $\mathrm{t}(0.05, \mathrm{~N}-1) \fallingdotseq 2$ とすると,

$$
\overline{\mathrm{x}}-2 \times \sigma / \sqrt{\mathrm{N}} \leqq \mu \leqq \overline{\mathrm{x}}+2 \times \sigma / \sqrt{\mathrm{N}}
$$

と表される。ここで,

$\mathrm{N}$ ：平均値の信頼区間を一定にするときの 1 年間の 採水頻度

$\overline{\mathrm{x}}$ : 年平均值

$\mu:$ 母平均値

$\sigma:$ 母標準偏差

である。信頼限界を平均値の $10 \%$ にするためには,

原データの場合 $\quad: 2 \times \sigma / \sqrt{\mathrm{N}}=0.1 \overline{\mathrm{x}} \quad(10)$

対数変換データの場合 : $2 \times \sigma / \sqrt{\mathrm{N}}=0.05$ (11)

と置き，Nを求める。ただし，対数変換データの場合， 信頼限界は, 平均值の $10 \%$ 強となる。(10), (11)式を変形 すると，それぞれ(12)，(13)式となる。

$$
\begin{aligned}
& \mathrm{N}=400 \times \sigma^{2} / \overline{\mathrm{x}}^{2} \\
& \mathrm{~N}=1600 \times \sigma^{2} \\
& \text { ここで, 現行の水質調查から予測される最大の総変 }
\end{aligned}
$$

動 $\mathrm{S}_{\max }$ を使い, 母標準偏差 $\sigma$ は,

$$
\sigma=\sqrt{\mathrm{S}_{\max } /(\mathrm{n}-1)}
$$

と推定できる。

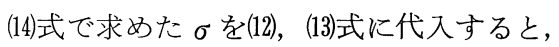

$$
\begin{aligned}
& \mathrm{N}=400 \times \mathrm{S}_{\max } /\left\{(\mathrm{n}-1) \times \overline{\mathrm{x}}^{2}\right\} \\
& \mathrm{N}=1600 \times \mathrm{S}_{\max } /(\mathrm{n}-1)
\end{aligned}
$$

となり，この式を用いて平均値の $95 \%$ 信頼限界を平均 值の $10 \%$ とする 1 年間の採水頻度を求める。

\section{5. 結果と考察}

\section{1 分散分析の結果}

(1)式は，採水した月が同じならば $\alpha_{i}$ が同じ值をと り, 採水した時間が同じならば $\beta_{j}$ が同じ值になること を意味している。残査 $\varepsilon_{i j}$ の原因には，降雨等の不規則 な変動の他に, 潮の干満のように本来は規則的な変化 をしているが, 採水間隔とは周期がずれるため, 見か け上不規則な変動を示しているものもある。このよう な理由で，(1)式がモデルとして妥当でない項目に, SS と塩素イオンがある。また, 調査目的が, 異常値の検 出を目的とする $\mathrm{pH}$ も，(1)式に当てはまらない項目と 言える。残査について正規性と等分散の検定を行った 結果, $\mathrm{pH}$ と $\mathrm{DO}$ 以外の項目は, 対数変換を行うことと した。

分離された時間変動と季節变動の例を, Fig. 2 に示 した。Fig. 2 はDOの例で，この地点では，時間変動は 日照により，季節変動は水温により変動していた。

分散分析の結果をTable 3に示した。Table 3 から, 1 日 4 回の調査項目は, SS を除き時間変動が有意とな る地点が多かったが，1日 2 回の調査項目は，有意と なる地点が少なかった。季節変動を見ると全ての項目 とも年12回の測定を行っているため, 有意となる地点 が多かった。季節変動と時間変動の結果から, 変動が 有意とならない原因は, 項目の特質ではなく, 採水頻 度にあると言え，1日2回の調査では，時間変動を十

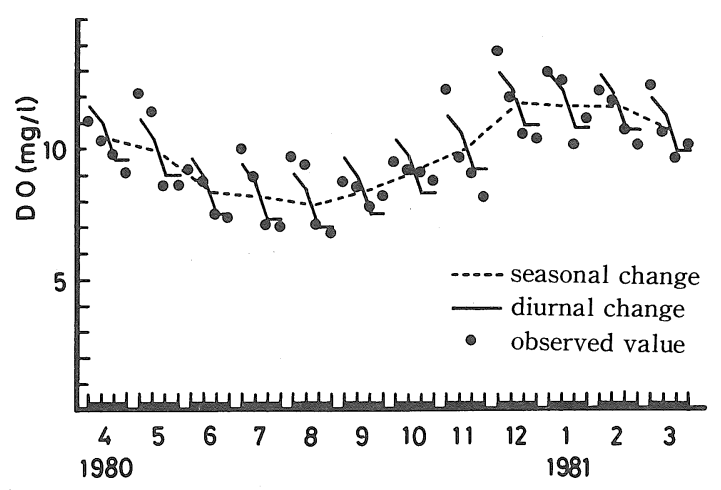

Fig. 2 Change of DO at Sagami-Ohhashi. 
Table 3 Number of locations with significant seasonal and diurnal variation ${ }^{+}$

\begin{tabular}{|c|c|c|c|c|c|c|}
\hline Factor Parameter & $\mathrm{pH}$ & DO & BOD & $\mathrm{COD}$ & SS & WQI \\
\hline Seasonal & 54 & 69 & 71 & 63 & 66 & 60 \\
\hline Diurnal & 51 & 67 & 47 & 41 & 20 & 52 \\
\hline Factor Parameter & $\mathrm{PO}_{4}-\mathrm{P}$ & $\mathrm{T}-\mathrm{N}$ & $\mathrm{NH}_{4}-\mathrm{N}$ & $\mathrm{NO}_{2}-\mathrm{N}$ & $\mathrm{NO}_{3}-\mathrm{N}$ & $\mathrm{Cl}^{-}$ \\
\hline Seasonal & 53 & 63 & 63 & 57 & 60 & 51 \\
\hline Diurnal & 6 & 12 & 14 & 20 & 9 & 17 \\
\hline
\end{tabular}

+ The number of sampling stations is 71 . Significance level of the F test is $1 \%$.

分に捕えられないためと言える。この理由は，生活系 排水の污濁排出パターンが 2 山型になって掞り，12時 間の採水間隔では同じ程度の污濁水を採水してしまう ためと考光られる。また，生活系排水による污濁以外 でもこのような例は見られ，感潮域の塩素イオンは典 型的な例である。しかし，1 日 2 回の調査結果を使っ て求めた WQI は, 時間変動が有意となる地点が多く, WQI の有効性を示していると言光る。

\section{2 現状の採水頻度における $\mathrm{k}$ とにの最適な組合 せ}

(7)，(8)式は，季節変動の分散 $\sigma_{\mathrm{A}}{ }^{2}$ と, 時間変動の分散 $\sigma_{\mathrm{B}}{ }^{2}$ を比較して, 変動の大きい要因の採水頻度を多くす ることを意味している。このため，年間の採水頻度が 同一の場合には, (7), (8)式の k とlの値のとき水質変動 の大きさを示す総変動 $\mathrm{S}_{\mathrm{T}}$ は最大となり，その地点に打 ける水質を適確に把握することができる。

(7)，(8)式により，現状の年間の採水頻度を固定して 求めた，水質を適確に捕光る $\mathrm{k}$ と の最適な組合せの 例として, DO と BOD の結果を Table 4 に示した。DO は，組合せの種類が多様で，全体にわたっているが， BOD では，季節変動を多く測定する方に偏っている。 これは, DO が飽和度の決まった項目で, 水量にはあま り影響されず, 水温, 日照量や BOD 等により増減する のに対し，BOD は，水量に影響されるため，人為污濁 による時間変動よりは，水量の季節変動による濃度変 化が大さいためと考兄られる。

\section{3 平均值の信頼限界を一定にするための $\mathbf{k}$ と の最適な組合せ}

Table 5 に, (15)式から求めた, DO の年平均值の $95 \%$ 信頼限界を，年平均值の $10 \%$ にしたときの最適な組合 せを示した。Table 6 には, (16)式から求めた BOD の結 果を示した。表を見やすくするため，採水頻度に上下 限を設け，組合せの数を限ってある。

組合せを見ると，5.2の結果と同様に，DOは多様な 組合せとなって怙り, BOD は季節変動を多く測定する
Table 4 Number of locations corresponding to each set which makes variation maximum under the present program

\begin{tabular}{|c|c|c|c|c|c|c|c|}
\hline \multirow{2}{*}{ Frequency } & $\begin{array}{c}\text { days } / \\
\text { year }\end{array}$ & 1 & 2 & 4 & 6 & 12 & 24 \\
\hline & $\begin{array}{c}\text { times } / \\
\text { day }\end{array}$ & 48 & 24 & 12 & 8 & 4 & 2 \\
\hline Number of & DO & 2 & 5 & 12 & 12 & 25 & 15 \\
\hline locations & $\mathrm{BOD}$ & & & 1 & 8 & 18 & 44 \\
\hline
\end{tabular}

Table 5 Number of locations corresponding to each set of the optimum seasonal and diurnal frequencies which makes variation maximum and confidence limit to be $10 \%$ (DO)

\begin{tabular}{|c|c|c|c|c|c|}
\hline times $/$ day days $/$ year & 2 & 4 & 6 & 12 & 24 \\
\hline 1 & 2 & 2 & 8 & 1 & 5 \\
\hline 2 & 1 & 2 & 4 & 2 & 0 \\
\hline 4 & 1 & 0 & 10 & 6 & 2 \\
\hline 8 & 2 & 5 & 1 & 2 & 0 \\
\hline 12 & 4 & 7 & 2 & 2 & 0 \\
\hline
\end{tabular}

Table 6 Number of locations corresponding to each set of the optimum seasonal and diurnal frequencies which makes variation maximum and confidence limit to be $10 \%$ (BOD)

\begin{tabular}{ccccccc}
\hline times $/$ day & days $/$ year & 2 & 4 & 6 & 12 & 24 \\
\hline 1 & 0 & 0 & 0 & 2 & 22 \\
2 & 0 & 0 & 0 & 7 & 11 \\
4 & 0 & 0 & 1 & 8 & 7 \\
8 & 0 & 1 & 2 & 6 & 0 \\
12 & 0 & 0 & 2 & 2 & 0 \\
\hline
\end{tabular}

方に偏っている。また, BOD の方が DO の 2 倍汪ど多 く測定する結果となって抢り，水質变動の大きい項目 と言光る。 


\section{6. ま と}

水質変動を季節変動と時間変動に分離し, 従来行わ れていなかった, 変動の大きさを考慮した解析方法を 示し, 神奈川県の水質データを利用して採水頻度の解 析を行った。その結果, 地点や項目により多様な採水 頻度の組合せが得られた。

地点により採水頻度に差をつけることは, 平均値の 信頼区間を各地点同一にするために必要なことと言え る。しかし, 項目毎の採水頻度については, 同一の污 濁源によると思われる項目や相互に関連のある項目 は, 污濁原因の解明や水質予測等のデータ利用の面か ら考光, 同一の採水頻度にする方が望皇しいと言光る。 そのためには, 関連のある項目のグループ化を行い, 結果を平均したり, WQI のような総合指標により, 最 適な組合せを求めることが必要と考光られる。

今回は, 地点間の比較をしやすくするため, 平均值 の信頼区間を同一にする採水頻度について解析を行っ たが, 最終的な採水頻度の決定には, 利水目的や費用 効果等も含めた総合的な検討が必要であり, 今後の課 題である。

（原稿受理 昭和59年 5 月 25 日）

\section{引用 文 献}

1) J.C. Loftis, R.C. Ward (1980) Water Quality Monitoring Some Practical Sampling Frequency Conciderations, Environmental Manegement, 4, No. 6, 521-526.

2 ) R.C. Ward, J.C. Loftis, K.S. Nielsen, R.D. Anderson (1979) Statistical Evaluation of Sampling Frequencies in Monitoring Network, Journal WPCF, 51, No. 9, 2292-2300.

3 ) R.C. Ward, K.S. Nielsen (1978) Evaluating The Sampling Frequencies of Water Quality Networks, USEPA, EPA-600/7-78-169.

4 ) 松岡譲, 内藤正明（1983）水質監視システムの合 理化に関する研究の現状と問題点一観測の時間的空 間的配置の適正化を中心として一, 水質污濁研究,

6, $1-13$.

$5 ） ７ ）$ 神奈川県 $(1979 ， 1980 ， 1981 ）$ 神奈川県水質 調査年表.

8 ) 吉見洋, 岡敬一, 井口潔, 関野廣子 (1982) 相模 川水系の水質解析について, 水質污濁研究, 5, 193200.

9 ) 岡敬一, 吉見洋, 井口潔, 小森谷廣子 (1983) 総 合水質指標による神奈川県内河川水質の解析, 水質 污濁研究， 6, 407-413. 